Supporting Information

\title{
Pore Size Engineering Enabled Selectivity Control in Tandem Catalytic Upgrading of Cyclopentanone on Zeolite Encapsulated Pt Nanoparticles
}

\author{
Hong Je Cho, Doyoung Kim, and Bingjun Xu* \\ Catalysis Center for Energy Innovation (CCEI) and Department of Chemical and Biomolecular \\ Engineering, University of Delaware, Newark, Delaware 19716, United States \\ *E-mail: bxu@udel.edu
}




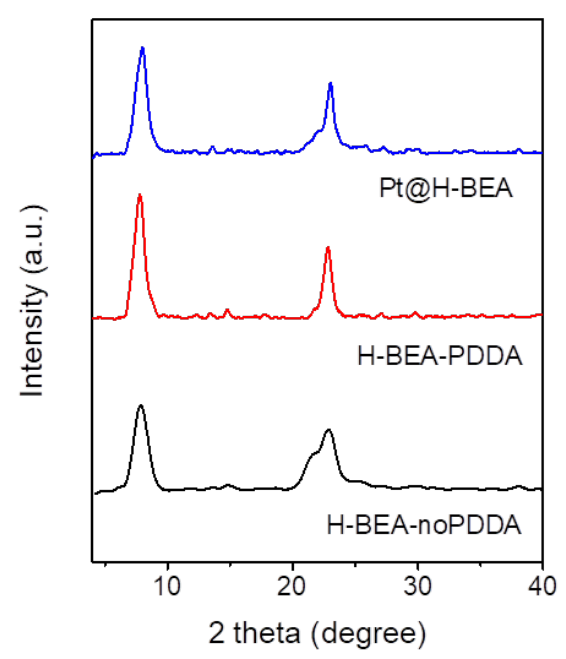

Figure S1. XRD patterns of Pt@H-BEA, H-BEA-PDDA and H-BEA-noPDDA. 

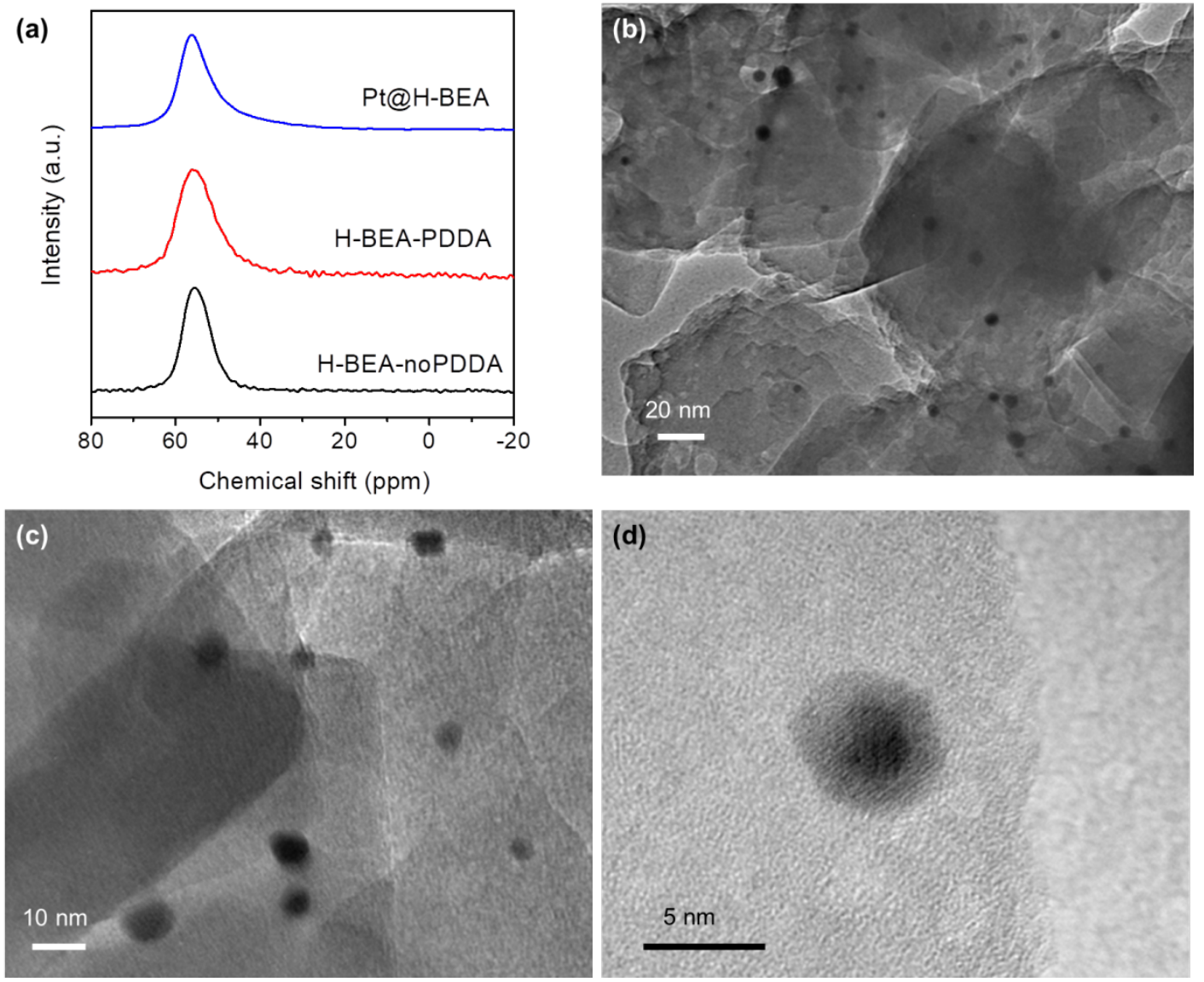

Figure S2. (a) ${ }^{27}$ Al MAS NMR spectra of Pt@H-BEA, H-BEA-PDDA and H-BEA-noPDDA samples, and (b-d) TEM images of Pt@H-BEA. 

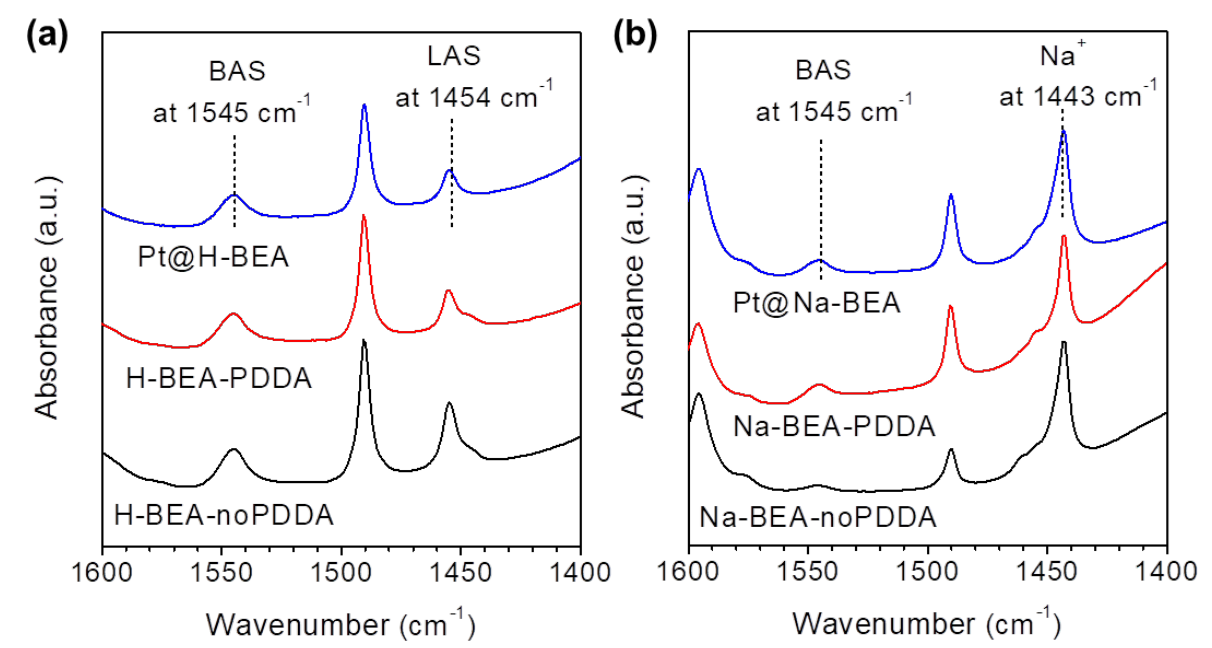

Figure S3. FTIR spectra of (a) Pt@H-BEA, H-BEA-PDDA and H-BEA-noPDDA and (b) Pt@Na-BEA, Na-BEA-PDDA and Na-BEA-noPDDA samples at $150{ }^{\circ} \mathrm{C}$ upon saturation of the samples with pyridine at $150^{\circ} \mathrm{C}$.

Note: On the spectra, the peaks at 1545, 1454 and $1443 \mathrm{~cm}^{-1}$ are assigned to BAS (Brønsted acid sites (BAS), Lewis acid sites (LAS) and Na cations, respectively. ${ }^{1-4}$

The density of Brønsted acid sites (BAS) for H-type zeolites is determined to be 156, 160 and 202 $\mu \mathrm{mol} \mathrm{g}{ }^{-1}$ for Pt@H-BEA, H-BEA-PDDA and H-BEA-noPDDA, respectively, in Figure S3a. The $\mathrm{Al}$ content based on the Si/Al ratio measured by XRF (Table S1) is determined to be 292, 297 and $320 \mu \mathrm{mol} \mathrm{g}{ }^{-1}$ for Pt@H-BEA, H-BEA-PDDA and H-BEA-noPDDA, respectively. Since no extraframework Al species is observed on the three samples $\left({ }^{27} \mathrm{Al}\right.$ MAS NMR, Figure S2a), the rest of framework $\mathrm{Al}$ species likely exhibit Lewis acidity, due to their perturbed coordination environment (Figure 3a). ${ }^{5-8}$ 
(a) Substrate-size selective hydrogenation
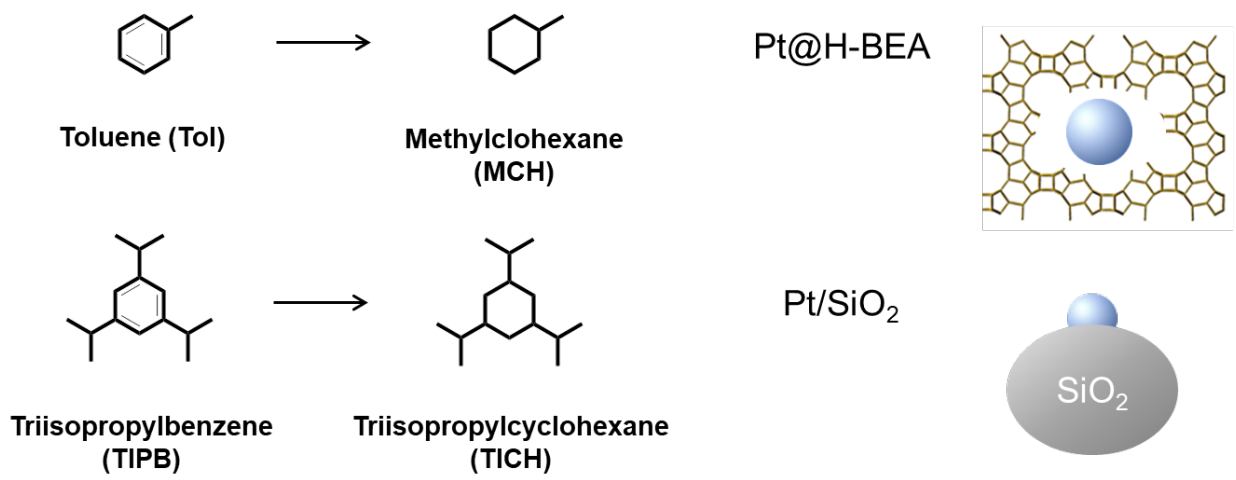

\section{(b) TOF (Turnover frequency)}

$=$ mol of product $/\left(\right.$ mol of $\mathrm{Pt}_{\text {surface }} \times$ time $\left.(\mathrm{h})\right)$ when substrate conversion $<10 \%$.

$$
\begin{aligned}
& X_{\text {sample }}=\text { TOF }_{\mathrm{TOl}} / \mathrm{TOF}_{\mathrm{TIPB}} \\
& Y_{\text {sample }}=X_{\text {sample }} / \boldsymbol{X}_{\mathrm{Pt} / \mathrm{SiO} 2} \\
& Z_{\text {sample }}=1-\mathbf{1} / Y_{\text {sample }} ; \text { Encapsulation degree }
\end{aligned}
$$

Figure S4. (a) Schematic of substrate-size selective hydrogenation of toluene and triisopropylbenzene over $\mathrm{Pt} @ \mathrm{H}-\mathrm{BEA}$ and $\mathrm{Pt} / \mathrm{SiO}_{2}$, and (b) equations used to quantify the degree of Pt NP encapsulation. 

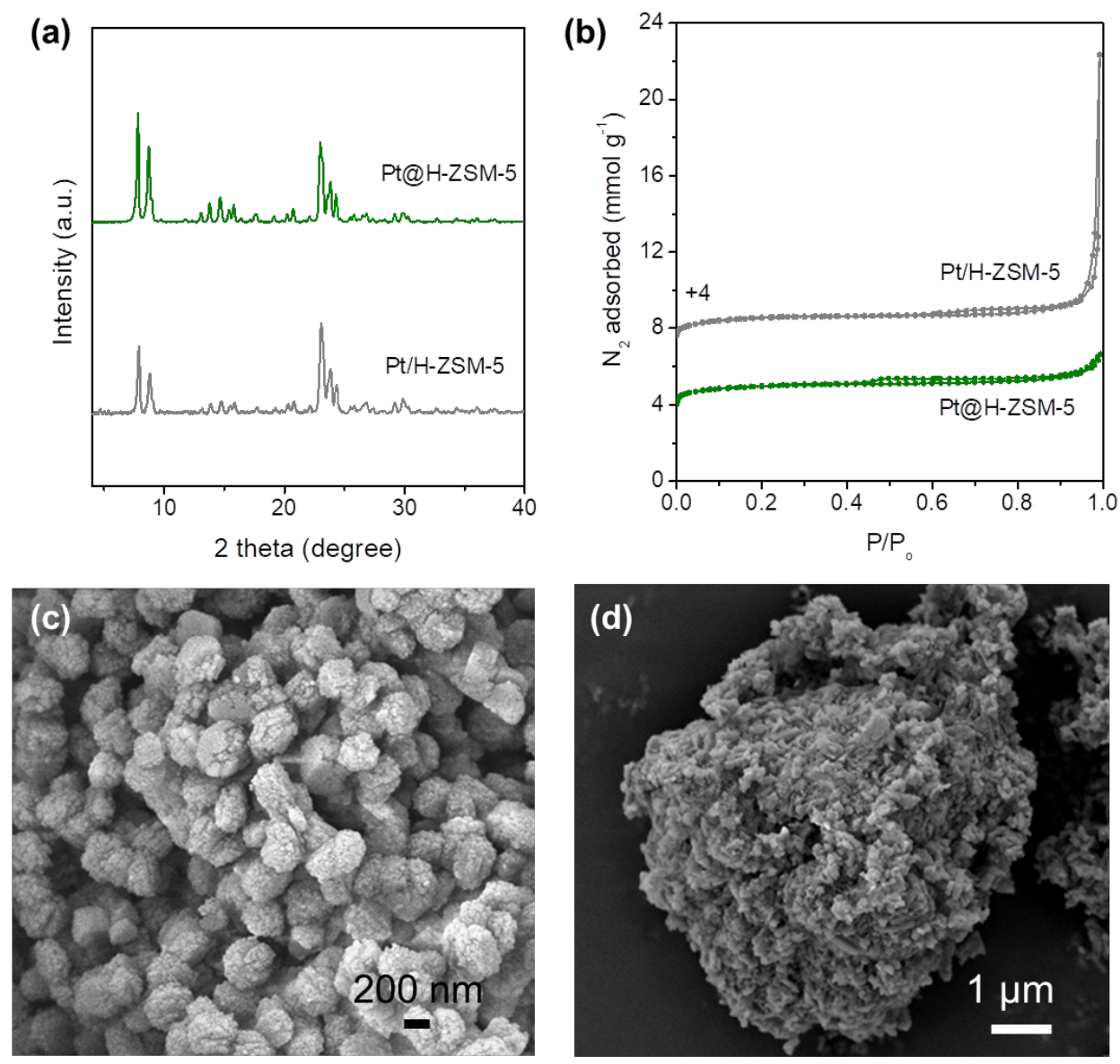

Figure S5. (a) XRD patterns, (b) $\mathrm{N}_{2}$ physisorption isotherms, and (c, d) SEM images of (c) Pt@H-ZSM-5 and (d) Pt/H-ZSM-5. 

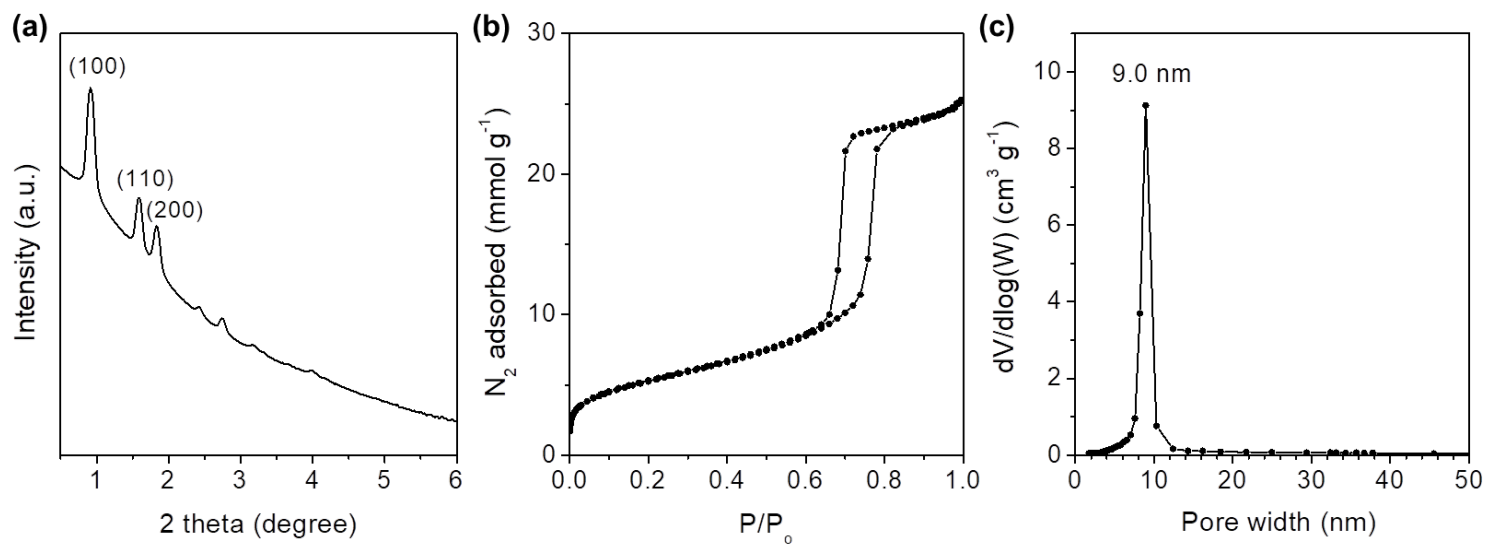

Figure S6. (a) XRD pattern at low angles, (b) $\mathrm{N}_{2}$ physisorption isotherm and (c) pore size distribution of H-Al-SBA-15. Pore size distribution is estimated from BJH method using adsorption branch in $\mathrm{N}_{2}$ physisorption isotherm.

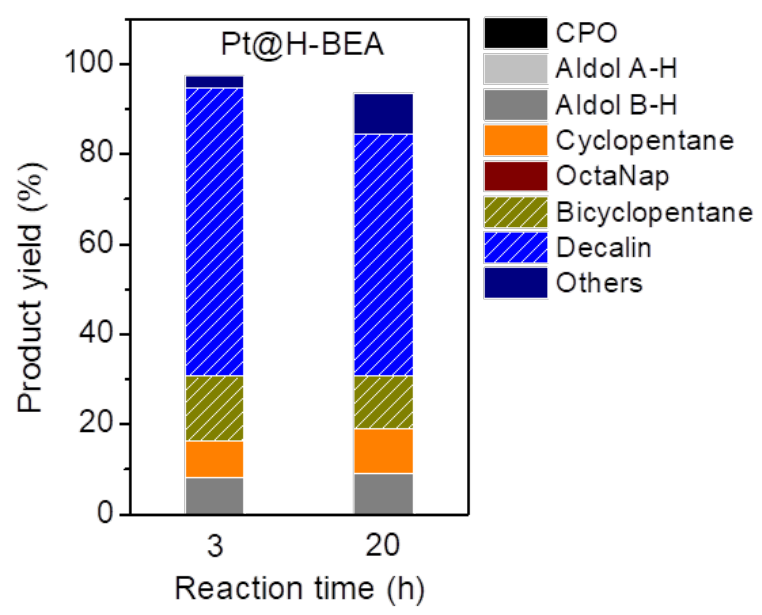

Figure S7. Product distribution of Pt@H-BEA in the conversion of CPO after $3 \mathrm{~h}$ and $20 \mathrm{~h}$ of reaction times. Reaction conditions: $0.5 \mathrm{mmol}$ of $\mathrm{CPO}$ and $1.5 \mathrm{~mL}$ of cyclohexane; $50 \mathrm{psi}$ of $\mathrm{H}_{2}$; $\mathrm{CPO} / \mathrm{Al}\left(\mathrm{mol} \mathrm{mol}^{-1}\right)=24 ; \mathrm{CPO} / \mathrm{Pt}\left(\mathrm{mol} \mathrm{mol}^{-1}\right)=437$; reaction temperature $170{ }^{\circ} \mathrm{C}$. "Others" in the plot is a combined yield of methylcylopentane and tricyclo $(4,4,0,0(3,8))$ decane. 

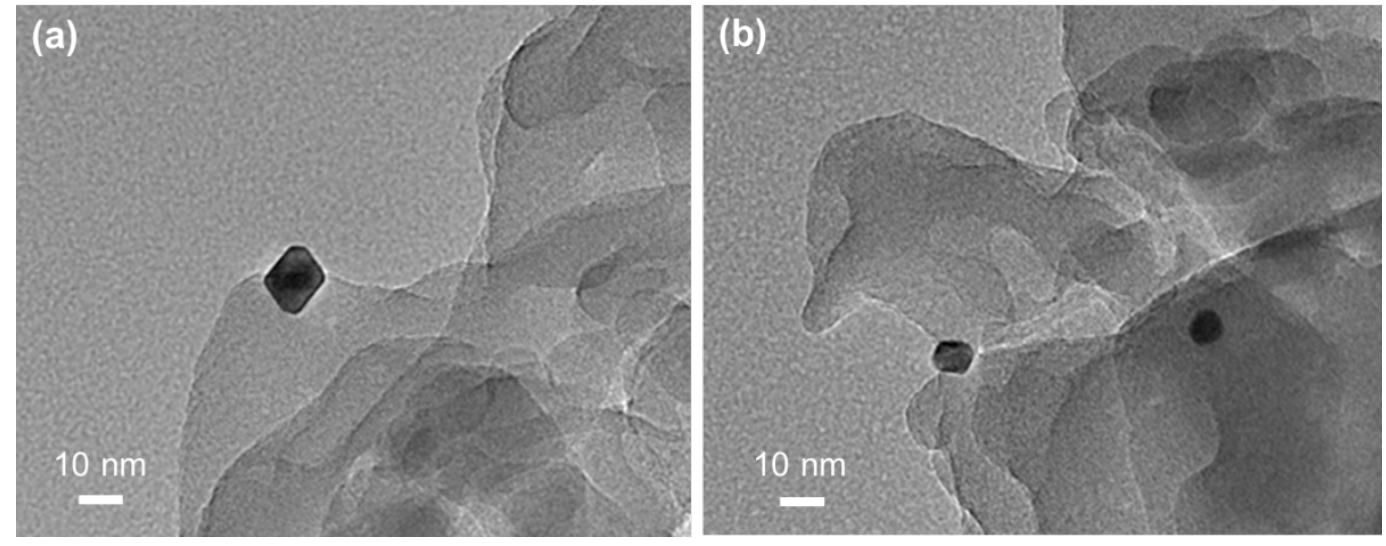

Figure S8. $(\mathrm{a}, \mathrm{b}) \mathrm{TEM}$ images of Pt@H-BEA with non-encapsulated Pt NPs, which account for $<10 \%$ of all Pt NPs in the sample.

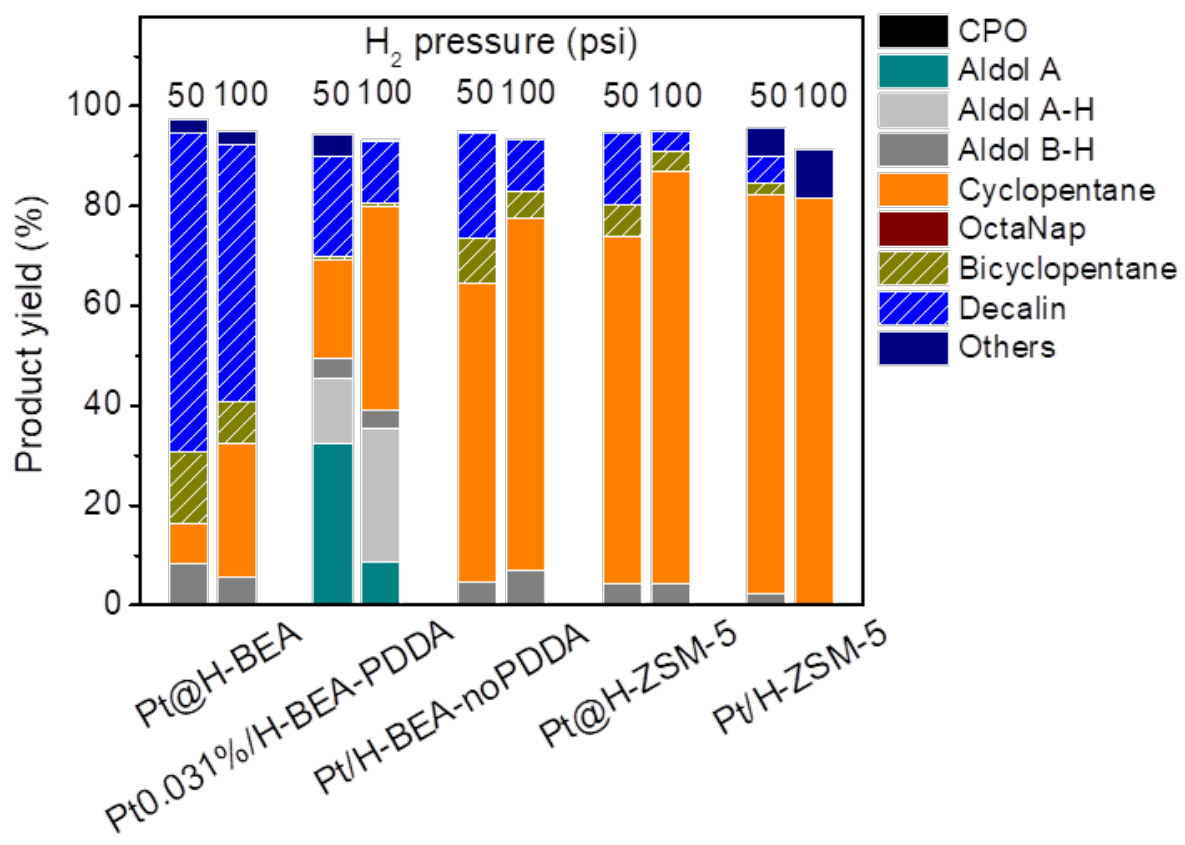

Figure S9. Catalytic impact of $\mathrm{H}_{2}$ pressure on product selectivity in the CPO conversion over Pt@H-BEA, Pt0.031\%/H-BEA-PDDA, Pt/H-BEA-noPDDA, Pt@H-ZSM-5 and Pt/H-ZSM-5 catalysts. Reaction conditions: $0.5 \mathrm{mmol}$ of $\mathrm{CPO}$ and $1.5 \mathrm{~mL}$ of cyclohexane; 50 or $100 \mathrm{psi}$ of $\mathrm{H}_{2}$; $3 \mathrm{~h}$ of reaction time; $\mathrm{CPO} / \mathrm{Al}\left(\mathrm{mol} \mathrm{mol}^{-1}\right)=24$; reaction temperature $170{ }^{\circ} \mathrm{C}$. 
(a)

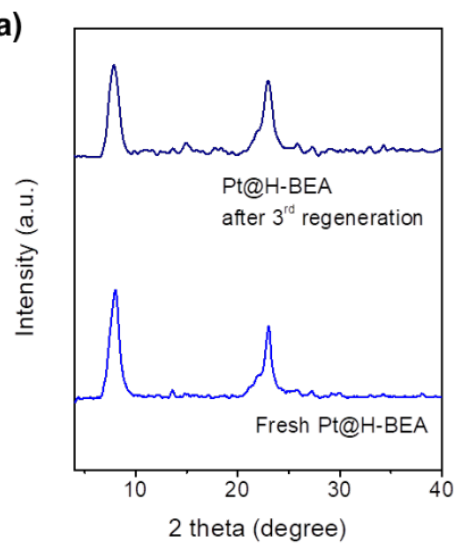

(b)

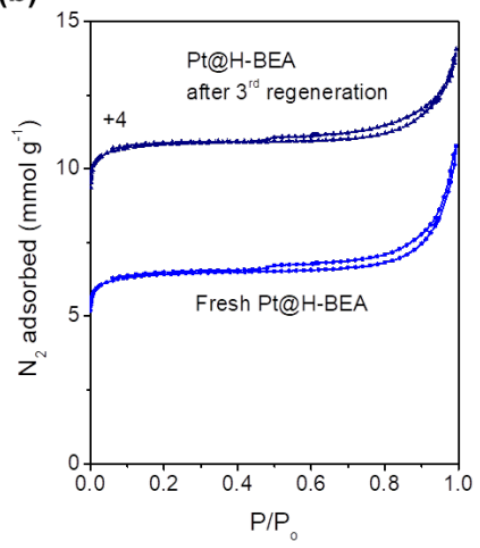

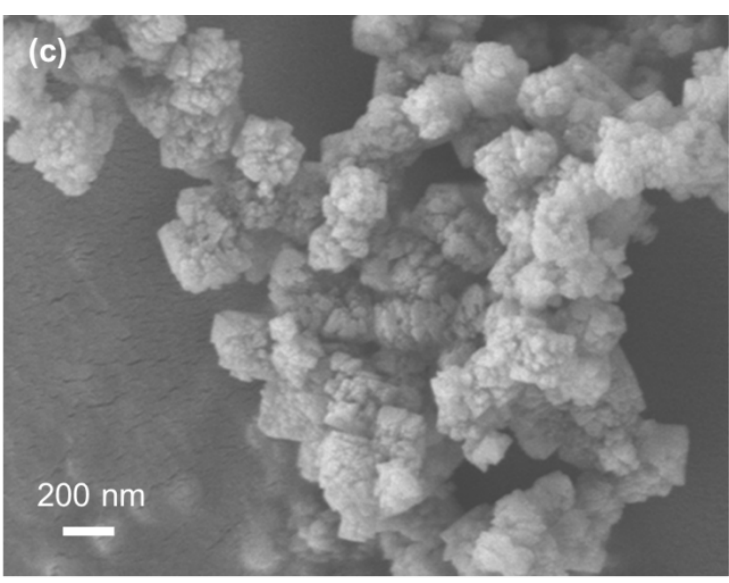

(d)

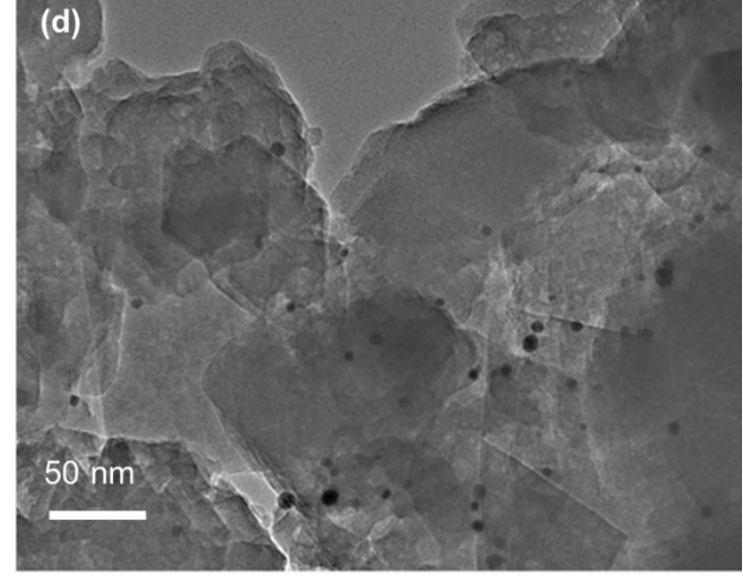

Figure S10. (a) XRD patterns and (b) $\mathrm{N}_{2}$ physisorption isotherms of fresh Pt@H-BEA and Pt@H-BEA after $3^{\text {rd }}$ regeneration, and (c) SEM image and (d) TEM image of Pt@H-BEA after $3^{\text {rd }}$ regeneration. 
Table S1. Physical and Chemical Properties of Prepared Samples

\begin{tabular}{ccccccc}
\hline Catalyst & $\begin{array}{c}\text { Nominal } \\
\mathrm{Si} / \mathrm{Al} \\
\left(\mathrm{mol} \mathrm{mol}^{-1}\right)\end{array}$ & $\begin{array}{c}\mathrm{Si}^{-\mathrm{Al}^{a}} \\
\left(\mathrm{~mol} \mathrm{~mol}^{-1}\right)\end{array}$ & $\begin{array}{c}\text { Pt loading }^{a} \\
\left(\mathrm{wt}^{a}\right)\end{array}$ & $\begin{array}{c}\text { Micropore } \\
\text { volume }^{b} \\
\left(\mathrm{~cm}^{3} \mathrm{~g}^{-1}\right)\end{array}$ & $\begin{array}{c}\mathrm{Pt} \mathrm{size}^{c} \\
(\mathrm{~nm})\end{array}$ & $\begin{array}{c}\mathrm{BAS} \mathrm{density}^{d} \\
\left(\mu \mathrm{mol} \mathrm{g}^{-1}\right)\end{array}$ \\
\hline Pt@Na-BEA & 60 & 57 & 0.31 & 0.20 & - & 76 \\
Na-BEA-PDDA & 60 & 56 & - & 0.20 & - & 78 \\
Na-BEA-noPDDA & 60 & 50 & - & 0.20 & - & 38 \\
Pt@H-BEA & 60 & 56 & 0.31 & 0.20 & $6.0(5.9)$ & 156 \\
H-BEA-PDDA & 60 & 55 & - & 0.20 & - & 160 \\
H-BEA-noPDDA & 60 & 51 & - & 0.20 & - & 202 \\
Pt/H-BEA-PDDA & 60 & 55 & 0.32 & 0.20 & $(5.8)$ & 155 \\
Pt/H-BEA-noPDDA & 60 & 51 & 0.30 & 0.20 & $(5.5)$ & 200 \\
Pt@H-ZSM-5 & 60 & 57 & 0.23 & 0.13 & $5.8(6.4)$ & 204 \\
Pt/H-ZSM-5 & 15 & 15.5 & 0.75 & 0.14 & $(5.7)$ & 652 \\
H-Al-SBA-15 & 5 & 5.3 & - & 0.01 & - & 114 \\
\hline
\end{tabular}

${ }^{a}$ Determined by XRF. ${ }^{b}$ Calculated with the $t$-plot method obtained from $\mathrm{N}_{2}$ physisorption isotherms. ${ }^{c}$ Determined from counting $>100$ particles on TEM images, and determined by CO chemisorption in parentheses under the assumption of a spherical geometry. ${ }^{d}$ Determined by the band at $1545 \mathrm{~cm}^{-1}$ on FTIR spectra with pyridine as the probe molecule at $150{ }^{\circ} \mathrm{C}$, with an error bar of $\pm 15 \%$. ${ }^{9,10}$ 
Table S2. Catalytic Results for Size-Selective Hydrogenation of Tol and TIPB ${ }^{a}$

\begin{tabular}{|c|c|c|c|c|c|}
\hline Catalyst & $\begin{array}{c}\mathrm{TOF}^{b}\left(\mathrm{~h}^{-1}\right) \\
\text { for Tol hydrogenation }\end{array}$ & $\begin{array}{c}\mathrm{TOF}^{b}\left(\mathrm{~h}^{-1}\right) \\
\text { for TIPB hydrogenation }\end{array}$ & $X^{c}$ & $Y^{d}$ & $Z^{e}$ \\
\hline $\mathrm{Pt} @ \mathrm{H}-\mathrm{BEA}$ & 9594 & 1060 & 9.05 & 10.98 & 0.909 \\
\hline Pt/H-BEA-PDDA & 9615 & 11099 & 0.87 & 1.05 & 0.048 \\
\hline Pt/H-BEA-noPDDA & 9832 & 11506 & 0.85 & 1.04 & 0.035 \\
\hline Pt0.031\%/H-BEA-PDDA & 9994 & 11631 & 0.86 & 1.04 & 0.040 \\
\hline Pt@H-ZSM-5 & 9882 & 1071 & 9.23 & 11.19 & 0.911 \\
\hline Pt/H-ZSM-5 & 9580 & 11111 & 0.86 & 1.05 & 0.044 \\
\hline $\mathrm{Pt} / \mathrm{SiO}_{2}$ & 9748 & 11822 & 0.82 & - & - \\
\hline
\end{tabular}

${ }^{a}$ Reaction conditions: $1.4 \mathrm{mmol}$ of Tol or TIPB in $3.2 \mathrm{~mL}$ of $n$-heptane; 400 psi of $\mathrm{H}_{2}$; reaction temperatures of $110^{\circ} \mathrm{C}$ and $130^{\circ} \mathrm{C}$ for the hydrogenation of Tol and TIPB, respectively. We have verified that the conversion of the reactant and yield of product linearly scaled with the catalyst loading at differential conversions.

${ }^{b} \mathrm{TOF}$ (turnover frequency) is defined as moles of product formed divided by moles of $\mathrm{Pt}_{\text {surface }}$ per reaction times $(\mathrm{h})$ under the kinetic regime (substrate conversion $<10 \%$ ).

${ }^{c} X_{\text {sample }}=\mathrm{TOF}_{\mathrm{Tol}} / \mathrm{TOF}_{\mathrm{TIPB}}$.

${ }^{d} Y_{\text {sample }}=X_{\text {sample }} / X_{\mathrm{Pt} / \mathrm{SiO} 2}$.

${ }^{e} Z_{\text {sample }}=1-1 / Y_{\text {sample }}$; Pt encapsulation degree for zeolite samples.

Table S3. Catalytic Results for Size-Selective Oxidation of Cy6-ol and Cy12-ol ${ }^{a}$

\begin{tabular}{lccccc}
\hline Catalyst & $\begin{array}{c}\mathrm{TOF}^{b}\left(\mathrm{~h}^{-1}\right) \\
\text { for Cy6-ol oxidation }\end{array}$ & $\begin{array}{c}\mathrm{TOF}^{b}\left(\mathrm{~h}^{-1}\right) \\
\text { for Cy12-ol oxidation }\end{array}$ & $X^{c}$ & $Y^{d}$ & $Z^{e}$ \\
\hline $\mathrm{Pt} @ \mathrm{H}-Z \mathrm{SM}-5$ & 32.4 & 1.1 & 29.5 & 11.8 & 0.92 \\
$\mathrm{Pt} @ \mathrm{H}-\mathrm{BEA}$ & 35.4 & 6.0 & 5.92 & 2.37 & 0.58 \\
$\mathrm{Pt} / \mathrm{SiO}_{2}$ & 36.2 & 14.5 & 2.50 & - & - \\
\hline
\end{tabular}

${ }^{a}$ Reaction conditions: $0.1 \mathrm{mmol}$ of Cy6-ol or Cy12-ol; $0.3 \mathrm{mmol}$ TBHP; $2 \mathrm{~mL}$ of acetonitrile; reaction temperature of $60{ }^{\circ} \mathrm{C}$. We have verified that the conversion of the reactant and yield of product linearly scaled with the catalyst loading at differential conversions.

${ }^{b}$ TOF is defined as moles of product formed divided by moles of $\mathrm{Pt}_{\text {surface }}$ per reaction times (h) under the kinetic regime (substrate conversion $<10 \%$ ).

${ }^{c} X_{\text {sample }}=\mathrm{TOF}_{\text {Cy6-ol }} / \mathrm{TOF}_{\mathrm{Cy} 12-\mathrm{ol}}$.

${ }^{d} Y_{\text {sample }}=X_{\text {sample }} / X_{\mathrm{Pt} / \mathrm{SiO} 2}$.

${ }^{e} Z_{\text {sample }}=1-1 / Y_{\text {sample }}$; Pt encapsulation degree for zeolite samples. 
Table S4. Physical and Chemical Properties of $3^{\text {rd }}$ Regenerated Pt@H-BEA

\begin{tabular}{ccccc}
\hline Catalyst & $\begin{array}{c}\mathrm{Si} / \mathrm{Al}^{a} \\
\left(\mathrm{~mol} \mathrm{~mol}^{-1}\right)\end{array}$ & $\begin{array}{c}\text { Pt loading }^{a} \\
(\mathrm{wt} \%)\end{array}$ & $\begin{array}{c}\text { Micropore volume }^{b} \\
\left(\mathrm{~cm}^{3} \mathrm{~g}^{-1}\right)\end{array}$ & $\mathrm{Pt} \mathrm{size}^{c}(\mathrm{~nm})$ \\
\hline Pt@H-BEA & 56 & 0.31 & 0.20 & $6.0(5.9)$ \\
$3^{\text {rd }}$ regenerated Pt@H-BEA & 56 & 0.31 & 0.20 & $(6.1)$ \\
\hline
\end{tabular}

${ }^{a}$ Determined by XRF. ${ }^{b}$ Calculated with the t-plot method obtained from $\mathrm{N}_{2}$ physisorption isotherms. ${ }^{c}$ Determined from counting $>100$ particles on TEM images, and determined by CO chemisorption in parentheses under the assumption of a spherical geometry.

Table S5. Catalytic Results for Size-Selective Hydrogenation of Tol and TIPB with $3^{\text {rd }}$ Regenerated Pt@H-BEA ${ }^{a}$

\begin{tabular}{lccccc}
\hline Catalyst & $\begin{array}{c}\mathrm{TOF}^{b}\left(\mathrm{~h}^{-1}\right) \\
\text { for Tol hydrogenation }\end{array}$ & $\begin{array}{c}\mathrm{TOF}^{b}\left(\mathrm{~h}^{-1}\right) \\
\text { for TIPB hydrogenation }\end{array}$ & $X^{c}$ & $Y^{d}$ & $Z^{e}$ \\
\hline $\mathrm{Pt} @ \mathrm{H}-\mathrm{BEA}$ & 9594 & 1060 & 9.05 & 10.98 & 0.909 \\
$3^{\text {rd }}$ regenerated Pt@H-BEA & 9714 & 1051 & 9.24 & 11.20 & 0.911 \\
$\mathrm{Pt} / \mathrm{SiO}_{2}$ & 9748 & 11822 & 0.82 & - & - \\
\hline
\end{tabular}

${ }^{a}$ Reaction conditions: $1.4 \mathrm{mmol}$ of Tol or TIPB in $3.2 \mathrm{~mL}$ of $n$-heptane; 400 psi of $\mathrm{H}_{2}$; reaction temperatures of $110^{\circ} \mathrm{C}$ and $130^{\circ} \mathrm{C}$ for the hydrogenation of Tol and TIPB, respectively. We have verified that the conversion of the reactant and yield of product linearly scaled with the catalyst loading at differential conversions.

${ }^{b}$ TOF is defined as moles of product formed divided by moles of $\mathrm{Pt}_{\text {surface }}$ per reaction times $(\mathrm{h})$ under the kinetic regime (substrate conversion $<10 \%$ ).

${ }^{c} X_{\text {sample }}=\mathrm{TOF}_{\mathrm{Tol}} / \mathrm{TOF}_{\mathrm{TIPB}}$.

${ }^{d} Y_{\text {sample }}=X_{\text {sample }} / X_{\mathrm{Pt} / \mathrm{SiO} 2}$.

${ }^{e} Z_{\text {sample }}=1-1 / Y_{\text {sample }}$; Pt encapsulation degree for zeolite samples. 


\section{References}

(1) Murphy, B. M.; Letterio, M. P.; Xu, B. J. Catalytic dehydration of methyl lactate: Reaction mechanism and selectivity control. J. Catal. 2016, 339, 21-30.

(2) Abu-Zied, B. M.; Schwieger, W.; Unger, A. Nitrous oxide decomposition over transition metal exchanged ZSM-5 zeolites prepared by the solid-state ionexchange method. Appl. Catal. B 2008, 84, 277-288.

(3) Pophal, C.; Yogo, T.; Yamada, K.; Segawa, K. Selective catalytic reduction of nitrous oxide over Fe-MFI in the presence of propene as reductant. Appl. Catal. B 1998, 16, 177-186.

(4) Cho, H. J.; Kim, D.; Xu, B. Selectivity Control in Tandem Catalytic Furfural Upgrading on Zeolite Encapsulated Pt Nanoparticles through Site and Solvent Engineering. ACS Catal. 2020, 10, 4770-4779.

(5) Brus, J.; Kobera, L.; Schoefberger, W.; Urbanova, M.; Klein, P.; Sazama, P.; Tabor, E.; Sklenak, S.; Fishchuk, A. V.; Dedecek, J. Structure of Framework Aluminum Lewis Sites and Perturbed Aluminum Atoms in Zeolites as Determined by Al-27\{H-1\} REDOR (3Q) MAS NMR Spectroscopy and DFT/Molecular Mechanics. Angew. Chem. Int. Ed. 2015, 54, 541-545.

(6) van Bokhoven, J. A.; van der Eerden, A. M. J.; Koningsberger, D. C. Threecoordinate aluminum in zeolites observed with in situ X-ray absorption near-edge spectroscopy at the AlK-edge: Flexibility of aluminum coordinations in zeolites. $J$. Am. Chem. Soc. 2003, 125, 7435-7442.

(7) Creyghton, E. J.; Ganeshie, S. D.; Downing, R. S.; vanBekkum, H. Stereoselective Meerwein-Ponndorf-Verley and Oppenauer reactions catalysed by zeolite BEA. $J$. Mol. Catal. A-Chem. 1997, 115, 457-472.

(8) Perez-Mayoral, E.; Matos, I.; Fonseca, I.; Cejka, J. Zeolites Efficiently Promote the Cyclization of Nonactivated Unsaturated Alcohols. Chem.-Eur. J. 2010, 16, 1207912082.

(9) Cho, H. J.; Kim, D. Y.; Li, S.; Su, D.; Ma, D.; Xu, B. Molecular Level Proximity of Metal and Acid Sites in Zeolite Encapsulated Pt Nanoparticles for Selective Multistep Tandem Catalysis. ACS Catal. 2020, 10, 3340-3348.

(10) Emeis, C. A. Determination of Integrated Molar Extinction Coefficients for Infrared-Absorption Bands of Pyridine Adsorbed on Solid Acid Catalysts. J. Catal. 1993, 141, 347-354. 